\title{
ASPEK KEPATUHAN SYARIAH PADA KARTU KREDIT SYARIAH DI INDONESIA
}

(Studi Kasus Pada Bank CIMB Niaga Syariah)

Oleh:

EDWIN RAHMAT YULIANTO, ME ${ }^{1}$

Edwinrahmatyulianto@gmail.com

Dosen Fakultas Agama Islam Universitas As Syafiiyah Jakarta

\begin{abstract}
ABSTRAK - Penelitian ini mengetahui aspek kepatuhan kartu kredit syariah berdasarkan fatwa DSN MUI. Syariah card merupakan produk perbankan syariah yang termasuk baru, sehingga dalam prakteknya perlu mendapatkan perhatian khusus agar sesuai dengan konsep syariah. Penerbitan syariah card sangat bermanfaat bagi masyarakat, terutama masyarakat yang beragama Islam, karena mempermudah masyarakat untuk melakukan pembayaran, memberikan rasa aman kepada masyarakat karena tidak perlu membawa uang yang banyak dan juga terbebas dari hal-hal yang dilarang oleh syariat. Salah satu bank yang mengeluarkan kartu kredit syariah adalah Bank Niaga Syariah dengan kartu syariah gold. Oleh karen itu Apakah kartu kredit tersebut sesuai dengan asas-asas syariah sehingga kartu kredit tersebut bisa di sebut kartu kredit syariah di Indonesia.
\end{abstract}

ABSTRACT - This study examines aspects of sharia credit card compliance based on the MUI DSN fatwa. Sharia card is a new sharia banking product, so in practice it needs to get special attention to fit the sharia concept. Sharia card issuance is very useful for the community, especially people who are Muslim, because it makes it easy for the community to make payments, provides a sense of security to the community because it does not need to carry a lot of money and is also free from things that are prohibited by the Shari'a. One of the banks that issue Islamic credit cards is Bank Niaga Syariah with a gold sharia card.

\footnotetext{
${ }^{1}$ Email : edwynrahmat@gmail.com
} 
Therefore whether the credit card is in accordance with the principles of sharia so that the credit card can be called a sharia credit card in Indonesia.

Keyword. Kartu kredit, kredit syari'ah, kepatuhan

\section{LATAR BELAKANG}

Di era mobilisasi seperti sekarang ini, penggunaan kartu kredit merupakan suatu kebutuhan. Hampir semua orang menginginkan sebuah pola hidup yang simpel dan juga praktis. Dimana segala sesuatunya bisa di lakukan dengan mudah tanpa kendala. Hal ini tentu saja bisa berjalan akibat adanya beragam teknologi dan juga beragam fasilitas yang bisa kita dapatkan, sehingga segala sesuatunya dapat kita lakukan dengan mudah dan nyaris tanpa hambatan.

Di Indonesia jumlah kartu kredit yang beredar mencapai $17.244 .127^{2}$ dengan jumlah penerbit kartu kredit mencapai 24 bank. ${ }^{3}$ Jumlah tersebut tergolong banyak walaupun jika kita melihat dari prosentase seluruh penduduk Indonesia yang mencapai 250 juta jiwa maka jumlah termasuk kecil dibawah 10\%. Dari 24 bank diatas semuanya merupakan bank konvensional. Hal tersebut sangat di sayangkan karna $70 \%$ penduduk Indonesia adalah beragama islam. Ini menjadi satu fenomena yang harus di lirik oleh perbankan Syariah di Indonesia untuk mengeluarkan produk-produk yang sesuai dengan ketentuan syariah, terutama Kartu Kredit. Karna pangsa pasar yang begitu besar.

Di Indonesia Kartu Kredit Syariah sudah diatur melalui Fatwa Dewan Syariah Nasional Majelis Ulama Indonesia (DSN-MUI) NO: 54/DSN-MUI/X/2006 Tentang SYARIAH CARD. Dan pada tahun 2007 Bank Indonesia (BI) mengeluarkan regulasi berupa Surat Bank Indonesia No.9/183/DPbS/2007 tentang kartu kredit syariah.. fatwa tersebut adalah jawaban dari kebutuhan umat islam di Indonesia dalam menggunakan kartu kredit yang sesuai dengan ketentuan syariah. MUI menilai bahwa dalam rangka memberikan kemudahan, keamanan, dan kenyamanan bagi nasabah dalam melakukan transaksi dan penarikan tunai, Bank Syariah dipandang perlu menyediakan sejenis Kartu Kredit, yaitu alat pembayaran dengan menggunakan kartu yang dapat digunakan untuk

\footnotetext{
${ }^{2}$ https://www.bi.go.id/id/statistik/sistempembayaran/apmk/contents/jumlah\%20apmk\%20bered ar.aspx

${ }^{3}$ https://www.bi.go.id/id/statistik/sistempembayaran/apmk/contents/penyelenggara\%20apmk.as $\mathrm{px}$
} 
melakukan pembayaran atas kewajiban yang timbul dari suatu kegiatan ekonomi, termasuk transaksi pembelanjaan dan atau untuk melakukan penarikan tunai, di mana kewajiban pembayaran pemegang kartu dijamin dan dipenuhi terlebih dahulu oleh acquirer atau penerbit, dan pemegang kartu berkewajiban melakukan pelunasan kewajiban pembayaran tersebut kepada penerbit pada waktu yang disepakati secara angsuran.

Dengan adanya fatwa DSN MUI tentang Syariah Card di Indonesia bukan berarti semua umat muslim di Indonesia bisa menggunakan kartu kredit tersebut secara bebas. Berbeda dengan kartu kredit konvensional yang menawarkan produk kartu kredit ke semua elemen masyarakat baik yang membutuhkan maupun tidak. Dalam konsep ekonomi syariah, salah satu perilaku yang harus dipegang teguh dan dijalani sebagai Muslim yang meyakini sistem syariah sebagai panduan hidup dalam memenuhi kebutuhan hidupnya, yaitu perilaku konsumen yang tidak boros/tidak bersikap konsumtif. Jangan sampai dengan penggunaan kartu kredit syariah tersebut maka pengguna jadi melakukan hal-hal yang malah bertentangan dengan gaya hidup yang sudah diajarkan oleh Al Qur'an dan Hadist sebagai pedoman kehidupan umat Islam.

Pada saat ini tidak semua bank syariah yang mengeluarkan produk syariah card di Indonesia. Hanya ada 2 bank yang mengeluarkan produk tersebut yaitu BNI Syariah dan Bank Niaga Syariah. Penulis ingin mengangkat persoalan pada produk Kartu Syariah Gold yang di keluarkan oleh Bank Niaga Syariah. Apakah produk tersebut dalam implementasinya sudah sesuai dengan prinsip-prinsip syariah, Bagaimana mekanisme perhitungan fee pada kartu kredit syariah ini dan bagaimana penggunaan akad pada kartu kredit syariah ini.

\section{LITERATUR REVIEW}

Kurniawan Rahmadianto (2013), melakukan penelitian Hasanah Card pada Bank BNI cabang kota malang, menjelaskan bahwa Hasanah Card merupakan produk yang masih baru bagi nasabah, oleh karena itu Bank BNI Syariah kota Malang seharusnya memberikan pengenalan terlebih dahulu untuk produk kartu kredit Hasanah Card ini. kartu kredit syariah ini memiliki biaya minimal dimana ini yang sering menjadi permasalahan apabila muncul tagihan bulanan. Nasabah sering mengabaikan biaya minimal ini dan akhirnya tagihannya membengkak dikarenakan biaya tersebut. Hal ini yang harus 
diberitahukan kepada nasabah yang ingin melakukan pengaplikasian kartu kredit Hasanah Card ini agar tidak terjadi adanya asymmetric informationdimana nasabah melupakan minimum payment tersebut. Selain itu, akibat terjadinya kredit macet yang disebabkan oleh nasabah yang lupa tidak membayar minimum payment-nya maka Bank BNI Syariah Malang harus memperketatpengawasannya terhadap nasabah yang menggunakan kartu kredit ini.

Dewi Sukma Kristianti (2014), dalam penelitiannya menjelaskan bahwa penggunaan kartu kredit syariah sebagai salah satu produk jasa bank syariah yang diperuntukan dalam kegiatan pembiayaan konsumer, memberikan pengaruh yang sangat besar dalam peningkatan kegiatan transaksi konsumsi masyarakat, khususnya masyarakat Muslim. Dikarenakan dalam kartu kredit syariah tidak ada sistem kontrol untuk memastikan apakah pemegang kartu menggunakan kartunya untuk membelanjakan barang-barang yang halal dan pagu batas penggunaan kartu tidak dapat menjadikan pemegangnya untuk tidak menjadi konsumtif. Padahal ini jelas-jelas bertentangan dengan prinsip syariah, sebab sifat konsumtif lebih menekankan pada kepuasan diri dalam memenuhi bidang materiil yang bersifat sesaat.

Nuradli Ridzwan Shah Bin Mohd Dali dan Hanifah Abdul Hamid (2007), dalam penelitianya di Malaysia menjelaskan Saat ini pelanggan lebih sadar tentang penggunaan kartu kredit Islam. Tidak hanya kartu kredit ini bebas bunga, tetapi tidak ada biaya keuntungan jika pembayaran penuh dilakukan sebelum tanggal jatuh tempo. Tidak seperti konvensional, pemegang kartu kredit Islam dapat mengetahui laba maksimum yang dibebankan kepada mereka dalam periode kontrak tertentu. Bai Al-Inahl, Al-Wadiah, dan Qardhul Hassan diterapkan dalam transaksi kartu kredit Islam. Dengan fitur-fitur ini, kartu kredit Islam didasarkan pada kontrak Syariah, yang bebas dari riba dan gharar, memiliki margin laba tetap, memberlakukan bunga nol persen pada rencana pembayaran mudah, memberikan fasilitas transfer saldo dan membebankan tingkat laba rendah pada saldo keseimbangan. Fitur-fitur dan manfaat kartu kredit Islam ini mendorong pelanggan Muslim dan Non Muslim untuk menerima kartu kredit Islam. Dan dapat disimpulkan bahwa ada 9 faktor yang dapat dianalisis lebih lanjut dalam menentukan motivasi bagi pemegang kartu kredit Islam. Semua faktor seperti Penggunaan dan Persepsi, Kepatuhan Bunga Gratis dan Kepatuhan Syariah, Kredit \& Kontrol, pembelian dan status Massal, Darurat dan 
Bepergian, Skema Pembayaran Mudah, Pengetahuan dan Kepatuhan Syariah, Status, dan kemudahan akses dapat berkontribusi dalam memperkaya pengetahuan tentang perilaku dan preferensi pemegang kartu kredit syariah.

\section{LANDASAN TEORI}

\section{Kartu Kredit Syariah}

Alat Pembayaran dengan Menggunakan Kartu (APMK) adalah alat pembayaran yang berupa kartu kredit, kartu Automated Teller Machine (ATM) dan/atau kartu debet. Kartu Kredit adalah APMK yang dapat digunakan untuk melakukan pembayaran atas kewajiban yang timbul dari suatu kegiatan ekonomi, termasuk transaksi pembelanjaan dan/atau untuk melakukan penarikan tunai, dimana kewajiban pembayaran pemegang kartu dipenuhi terlebih dahulu oleh acquirer atau penerbit, dan pemegang kartu berkewajiban untuk melakukan pembayaran pada waktu yang disepakati baik dengan pelunasan secara sekaligus (charge card) ataupun dengan pembayaran secara angsuran. ${ }^{4}$ Secara umum peraturan kartu kredit di Indonesia diatur melalui perarturan Bank Indonesia no No.14/2/PBI/2012, peraturan ini Perubahan Atas Peraturan Bank Indonesia No.11/11/PBI/2009 tentang Penyelenggaraan Kegiatan Alat Pembayaran Dengan Menggunakan Kartu.

Dalam ekonomi islam Istilah kartu kredit yang lazim dipakai oleh para ekonom dan praktisi perbankan syariah adalah bith'aqah al-'itim'aniyyah. Secara etimologi, kata bith'aqah berarti kartu. Pengertian kata "kartu" menurut tata bahasa adalah potongan kertas kecil atau dari bahan lain, di atasnya ditulis penjelasan yang berkaitan dengan potongan kertas itu. Sedangkan pengertian dari kata al-i'tim'aniyyah secara etimologi adalah saling percaya atau kondisi aman. ${ }^{5}$ Di Indonesia Ide penggunaan syari' ah card mulai muncul pada awal tahun $2003 .{ }^{6}$ Sejak saat itu wacana penggunaan syari'ah card mengalami perdebatan panjang hingga sampai saat ini. Perdebatan panjang tersebut terjadi baik dalam teori maupun praktik. Perspektif teori masih banyak yang mengatakan bahwa syari'ah card lebih mendekatkan diri kepada sifat israf (berlebih-lebihan) sehingga mendorong umat Islam

\footnotetext{
${ }^{4}$ https://www.bi.go.id/id/statistik/metadata/sistempembayaran/.../MetadataAPMK.pdf

5 Abdul Wahab Ibrahim Abu Sulaiman, Banking Cards Syariah Kartu Kredit dan Debitdalam Perspektif Fiqih, (Jakarta: Raja Grafindo Persada, 2006), h. 2.

6 Muhammad Syafi' I Antonio, "Modal”, Majalah Islami Bulanan, Edisi No. 8, (1 Juni 2003), hal. 13.
} 
bersikap konsumtif ,boros dan membiasakan untuk berutang. Namun di lain hal ada juga yang berpendapat jika sifat israf tersebut dibatasi maka akan dapat mengontrol hal tersebut. $^{7}$

Menurut dewan syariah nasional (DSN) kartu kredit syariah adalah merupakan kartu yang diterbitkan oleh bank syariah dalam rangka memenuhi kebutuhan masyarakat akan adanya kartu kredit yang bebas bunga. Fatwa tersebut diatur dalam Fatwa Dewan Syariah Nasional Majelis Ulama Indonesia (DSN-MUI) No. 54/DSN-MUI/X/2006 dan di dalam fatwa tersebut juga di jelaskan akad-akad yang terkandung di dalamnya, yaitu :

Pertama akad Ijarah, Transaksi Ijarah dilandasi adanya perpindahan manfaat (hak Guna), bukan perpindahan kepemilikan (hak milik). Jadi pada dasarnya prinsip ijarah sama saja dengan prinsip jual beli, tapi perbedaanya terletak pada objek transaksinya. Bila pada jual beli objek transaksinya barang, pada ijarah objek transaksinya adalah barang dan jasa. Pada dasarnya Ijarah didefinisikan sebagai hak untuk memanfaatkan barang/jasa dengan membayar imbalan tertentu. ${ }^{8}$ Menurut fatwa Dewan Syariah Nasional, ijarah adalah akad pemindahan hak guna (manfaat) atas suatu barang atau jasa dalam waktu tertentu melalui pembayaran sewa/upah, tanpa diikuti dengan pemindahan kepemilikan barang itu sendiri. ${ }^{9}$ Dalam konteks kartu kredit syariah, penerbit Kartu adalah penyedia jasa sistem pembayaran dan pelayanan terhadap Pemegang Kartu. Atas Ijarah ini, Pemegang Kartu dikenakan membership fee.

Kedua akad Qardh, yaitu pinjaman yang diberikan tanpa menyaratkan apapun dan mengembalikan pinjaman tersebut setelah jangka waktu tertentu. akad qard merupakan akad tabarru' yaitu segala macam perjanjian yang menyangkut non profit transaction (transaksi nirlaba). ${ }^{10}$ Dalam hal ini penerbit kartu adalah pemberi pinjaman (muqridh) kepada pemegang kartu (muqtaridh) melalui penarikan tunai dari bank atau ATM bank penerbit kartu.

Ketiga akad Kafalah, jaminan yang diberikan oleh penanggung ( $k a f i l$ ) kepada pihak ketiga untuk memenuhi kewajiban pihak kedua atau yang ditanggung. Dalam pengertian

\footnotetext{
7 Syariah card (kartu kredit syariah) ditinjau dari asas utilitas dan maslahah, Hengki firmanda, volume 4 no. 2, februari-juli 2014

8 Adiwarman Karim, Bank Islam analisis Fiqih dan keuangan. (raja grafindo persada, 2010) hal. 138

9 Fatwa Dewan Syariah nasional No. 09/DSN-MUI?IV/2000 tentang pembiayaan ijarah.

10 Adiwarman Karim, Bank Islam analisis Fiqih dan keuangan. (raja grafindo persada, 2010) hal. 68
} 
lain, kafâlah juga berarti mengalihkan tanggung jawab seseorang yang dijamin dengan berpegang pada tanggung jawab orang lain sebagai penjamin. ${ }^{11}$ dalam hal ini Penerbit Kartu adalah penjamin (kafil) bagi Pemegang Kartu terhadap Merchant atas semua kewajiban bayar (dayn) yang timbul dari transaksi antara Pemegang Kartu dengan Merchant, dan/atau penarikan tunai dari selain bank atau ATM bank Penerbit Kartu. Atas pemberian Kafalah, penerbit kartu dapat menerima fee (ujrah kafalah).

\section{Kriteria Pengguna Kartu Kredit Syariah}

Kriteria yang diberikan kepada pengguna kartu kredit syariah hanya diberikan kepada nasabah yang memiliki pendapatan/gaji yang layak dan sesuai dengan kebutuhan, pengguna kartu harus memiliki kemampuan secara financial untuk melunasi pembayaran pada waktunya. Ketentuan tersebut dilakukan untuk menghindari ketidakmampuan membayar di saat penagihan. Disamping kriteria tersebut kartu kredit syariah akan diberikan batasan dari besaran pembelanjaan atas transaksi yang dilakukan oleh pihak pengguna kartu (nasabah), ada batasan maksimal yang di patok oleh pihak penerbit kartu kredit syariah di saat nasabah melakukan transaksi. Hal ini untuk menghindari atas penggunaan dana bank syariah secara berlebih-lebihan (israf) yang pada akhirnya dikhawatirkan nasabah pengguna kartu tidak mampu membayar. ${ }^{12}$

\section{Perbedaan Kartu Kredit Syariah dan Konvensional}

Perbedaan kartu kredit syariah dan konvensional terletak pada perhitungan biaya bunga, pemegang kartu kredit konvensional dikatakan sebagai peminjam uang, maka akan dikenakan bunga (finace charge) yang timbul karena peminjaman uang dengan tingkat bunga sesuai periode waktu, untuk satu tahun disebut tingkat bunga per tahun, untuk satu bulan disebut tingkat bunga per bulan dan untuk satu hari dinamakan tingkat bunga per hari. Bunga dikenakan ketika card holder tidak membayar penuh tagihannya atau melakukan pembayaran minimum (minimum payment) sebelum tanggal jatuh tempo, terlambat membayar tagihan, melakukan transaksi penarikan uang tunai (cash advance).

\footnotetext{
11 Syafi'I Antonio, bank Syariah Dari Teori Ke Praktek, hal 123-125

12 https://ridaingz.wordpress.com/2015/01/02/konsep-kartu-kredit-bithaqah-itiman-sebagai-alatpembayaran-dalam-hukum-islam/
} 
Contohnya bunga pembelanjaan dan penarikan yang berlaku di bank danamon sebesar $3,5 \%$.

Bunga atau riba sendiri sudah di larang dalam agama Islam. Umat Islam dilarang untuk mendapatkan harta dengan cara yang zalim (QS an Nisa : 29). Sedangkan riba/bunga merupakan sebuah kezaliman. Islam dalam memperkeras persoalan haramnya riba, semata-mata demi melindungi kemaslahatan manusia, baik dari segi akhlak, masyarakat, maupun perekonomian. ${ }^{13}$ Dalam ilmu fiqih, di kenal dengan 3 jenis riba yaitu : Riba Fadl, biasa disebut juga riba buyu' yaitu riba yang timbul akibat pertukaran barang sejenis yang tidak memenuhi kriteria sama kualitasnya, sama kuantitasnya dan sama waktu penyerahannya. Contohnya adalah membeli emas dengan cara tidak tunai, menukar mata uang tidak pada saat waktu yang sama penyerahannya, atau menukar uang dengan uang dengan ada kelebihan pembayaran seperti menukar uang kecil pada saat lebaran. ${ }^{14}$ Riba Nasi'ah, biasa disebut riba duyun yaitu riba yang timbul akibat utang-piutang yang tidak memenuhi kriteria untung muncul bersama resiko (al ghunmu bil ghurmi) dan hasil usaha muncul bersama biaya (al-kharaj bi dhaman). Contohnya bunga deposito, tabungan, giro, pembayaran Bunga kartu kredit dll. ${ }^{15}$ Riba jahiliah, yaitu utang yang dibayar melebihi pokok pinjaman pada waktu yang telah di tetapkan. Contohnya denda keterlambatan pembayaran pada kartu kredit. $^{16}$

Berbeda dengan kartu kredit konvensional, Ketentuan Fee kartu kredit syariah tidak menggunakan system bunga melainkan diatur sebagai berikut Pertama, Iuran keanggotaan (membership fee) Penerbit Kartu berhak menerima iuran keanggotaan (rusum al'udhwiyah) termasuk perpanjangan masa keanggotaan dari pemegang Kartu sebagai imbalan (ujrah) atas izin penggunaan fasilitas kartu. Kedua, Merchant fee Penerbit Kartu boleh menerima fee yang diambil dari harga objek transaksi atau pelayanan sebagai upah/imbalan (ujrah) atas perantara (samsarah), pemasaran (taswiq) dan penagihan (tahsil al-dayn). Ketiga, Fee penarikan uang tunai Penerbit kartu boleh menerima fee penarikan uang tunai (rusum sahb al-nuqud) sebagai fee atas pelayanan dan penggunaan fasilitas yang

13 DR. Yusuf Qardhawi, Halal dan Haram, Jabal, hal. 239

14 Adiwarman Karim, Bank Islam analisis Fiqih dan keuangan. (Raja Grafindo Persada, 2010) hal. 36

15 Adiwarman Karim, Bank Islam analisis Fiqih dan keuangan. (Raja Grafindo Persada, 2010) hal. 38

16 Adiwarman Karim, Bank Islam analisis Fiqih dan keuangan. (Raja Grafindo Persada, 2010) hal. 40 
besarnya tidak dikaitkan dengan jumlah penarikan. Keempat, Fee Kafalah Penerbit kartu boleh menerima fee dari Pemegang Kartu atas pemberian Kafalah. Kelima, Semua bentuk fee tersebut di atas (a sampai dengan d) harus ditetapkan pada saat akad aplikasi kartu secara jelas dan tetap, kecuali untuk merchant fee. ${ }^{17}$

Ketentuan Ta'widh (ganti rugi) dan Denda berbeda dengan bank konvensional yang dikenakan Bunga. Dalam kartu kredit syariah Ta'widh Penerbit Kartu dapat mengenakan $t a$ 'widh, yaitu ganti rugi terhadap biaya-biaya yang dikeluarkan oleh Penerbit Kartu akibat keterlambatan pemegang kartu dalam membayar kewajibannya yang telah jatuh tempo. Denda keterlambatan (late charge) Penerbit kartu dapat mengenakan denda keterlambatan pembayaran yang akan diakui seluruhnya sebagai dana sosial. ${ }^{18}$

Kemudian tentang batasan-batasan kartu kredit syariah yaitu (1) Tidak boleh menimbulkan riba. (2) Tidak boleh digunakan untuk transaksi objek yang haram atau maksiat. (3) Tidak mendorong isrâf (pemborosan) antara lain dengan menetapkan pagu maksimal pembelanjaan. (4) Tidak mengakibatkan hutang yang tidak pernah lunas (ghalabah al-dayn). (5) Pemegang kartu utama harus memiliki kemampuan finansial untuk melunasi tepat pada waktunya. (6) Penerbit kartu tidak diperbolehkan memberikan fasilitas yang bertentangan dengan syariah. ${ }^{19}$

\section{METODOLOGI PENELITIAN}

Dalam penelitian ini metode yang digunakan adalah Kualitatif (qualitative reaserch) yaitu mengkaji perspektif partisipan dengan strategi-strategi yang bersifat interaktif dan fleksibel. Penelitian kualitatif ditujukan untuk memahami fenomenafenomena sosial dari sudut pandang partisipan. Dengan demikian arti atau pengertian penelitian kualitatif tersebut adalah penelitian yang digunakan untuk meneliti pada kondisi objek alamiah dimana peneliti merupakan instrumen kunci (Sugiyono, 2005). Menurut Sukmadinata (2005) dasar penelitian kualitatif adalah konstruktivisme yang berasumsi bahwa kenyataan itu berdimensi jamak, interaktif dan suatu pertukaran pengalaman sosial yang diinterpretasikan oleh setiap individu. Peneliti kualitatif percaya bahwa kebenaran

\footnotetext{
17 Fatwa DSN MUI NO: 54/DSN-MUI/X/2006 Tentang Syariah Card

18 Ibid,

${ }^{19}$ Ibid,
} 
adalah dinamis dan dapat ditemukan hanya melalui penelaahan terhadap orang-orang melalui interaksinya dengan situasi sosial mereka (Danim, 2002).

Metode penelitian ini bersifat deskriptif analisis, Data yang diperoleh seperti hasil pengamatan, hasil wawancara, analisis dokumen, catatan lapangan, disusun peneliti di lokasi penelitian,. Dalam penelitian ini penulis terlibat langsung dalam fenomena yang di teliti. informan yang penulis teliti merupakan pegawai di Bank Niaga Syariah yang bekerja sebagai customer service kartu kredit, kemudian cardholder sebagai pengguna dari Kartu Gold Syariah.

\section{PENELITIAN DAN PEMBAHASAN}

CIMB Niaga Syariah adalah Unit Usaha Syariah (UUS) PT Bank CIMB Niaga Tbk untuk merespon perkembangan bisnis perbankan syariah di Indonesia dan permintaan masyarakat terhadap layanan perbankan universal yang inovatif, lebih aman dan menguntungkan. Dalam perjalananya CIMB Niaga Syariah telah mendapatkan berbagai penghargaan. ${ }^{20}$

Kartu Gold Syariah, kartu yang di keluarkan oleh CIMB Niaga Syariah merupakan produk yang mengakomodir gaya hidup syariah, sehingga seluruh transaksinya yang dilakukan sudah dicover dengan akad-akad sesuai prinsip syariah. ${ }^{21}$ Dalam pengajuan Kartu Gold Syariah, pengguna di berikan formulir yang sama dengan formulir pengajuan kartu kredit konvensional. Karena divisi dari Kartu Kredit Syariah masih sama dengan divisi Kartu Kredit Konvensional. Di awal pengajuannya pengguna tidak di jelaskan secara detail oleh marketing kartu kredit mengenai informasi akad-akad apa saja yang digunakan oleh Kartu Gold Syariah tersebut. Dan ketika pengguna ingin bertanya kepada customer service Kartu Gold Syariah, customer service pun belum mengetahui secara detail tentang prinsip-prinsip syariah yang diterapkan oleh Kartu Kredit Syariah.

Akad yang di gunakan dalam Kartu Syariah Gold adalah akad kafalah (akan penjamin), akad Qardh (akad pinjam meminjam) dan Ijarah (akad pembiayaan jasa). Jika kita mengacu kepada fatwa DSN (DSN-MUI) No. 54/DSN-MUI/X/2006 tentang syariah

\footnotetext{
20 https://www.cimbniaga.com/in/personal/news-and-promotions/news/cimb-niaga-syariahandalkan-produk-unggulan-di-2017.html

21 https://www.cimbniaga.com/syariah/in/personal/products/cards/credit-card/syariah-goldcard.html
} 
card, maka kartu Gold Syariah dalam akadnya sudah sesaui dengan fatwa tersebut, yaitu menggunakan akad Kafalah, Qardh dan Ijarah. Namun dalam implementasinya ada tambahan beberapa akad seperti wakalah wal murabahah, wakalah wal ijarah, murabahah, ijarah, dan sharf sebagai tambahan fasilitas penggunaan kartu kredit. Dengan adanya tambahan beberapa akad untuk tambahan fasilitas maka fatwa DSN-MUI belum menjelaskannya.

Dalam syarat dan ketentuan kartu ini, di fungsi dan penggunaan kartu dikatakan "kartu syariah dapat di gunakan untuk transaksi pembelanjaan retail yang sah pada merchant yang menerima kartu MasterCard di seluruh dunia”. Bisa di katakan pengguna Kartu Gold Syariah bisa melakukan transaksi diseluruh merchant yang menggunakan MasterCard, yang diperbolehkan maupun yang tidak diperbolehkan dalam islam. Namun dalam hasil wawancara penulis dengan pengguna, Kartu Gold Syariah tidak dapat digunakan ditempat yang tidak sesuai prinsip syariah seperti Bar, diskotik, tempat perjudian, dll. Fakta tersebut sudah sesuai dengan fatwa (DSN-MUI) No. 54/DSNMUI/X/2006 tentang batasan-batasan penggunaan kartu salah satunya yaitu tidak boleh digunakan untuk transaksi objek yang haram dan maksiat.

Denda ta'wid (keterlambatan) Kartu Gold Syariah sebesar 135.000 flat perbulan, penggunaan ta'wid sudah diatur dalam Fatwa (DSN-MUI) No. 54/DSN-MUI/X/2006 pada bagian keenam tentang ta'wid dan denda. Dalam implementasinya ada sedikit catatan, Penentuan ta'widh ini tidak sesuai dengan ketentuan Fatwa karena telah ditentukan pada awal akad, sedangkan menurut ketentuan fatwa yang ada, nilai ta'widh tidak boleh ditentukan pada awal. Menurut DSN-MUI denda ta'wid harus digunakan untuk kegiata social, dalam wawancara, customer service belum mengetahui penggunaan denda ta'wid tersebut.

Kartu Gold Syariah menerapkan fee kartu kredit sebesar Rp 100.000,- untuk over limit pemakaian Kartu Gold Syariah yaitu pemakaian diatas pagu yang diberikan. Hal ini belum diatur dalam Fatwa (DSN-MUI) No. 54/DSN-MUI/X/2006. Tetapi jika kita mengkaji dari beberapa batasan-batasan untuk tidak mendorong israf (pemborosan) maka pemakaian diatas pagu seharusnya tidak dibenarkan karena dapat mendorong pemakaian diatas batas kemampuan. 
Dalam Tarik tunai kartu gold syariah menetapkan sebesar Rp 50.000,- per transaksi, hal tersebut sesuai Fatwa (DSN-MUI) No. 54/DSN-MUI/X/2006 bagian kelima tentang ketentuan fee, yaitu Penerbit kartu boleh menerima fee penarikan uang tunai (rusum sahb al-nuqud) sebagai fee atas pelayanan dan penggunaan fasilitas yang besarnya tidak dikaitkan dengan jumlah penarikan.

\section{KESIMPULAN DAN SARAN}

Dengan adanya Kartu Gold Syariah sejak 2010 tentu sangat membantu umat muslim di Indonesia untuk bisa memilih dan mendapatkan kartu kredit dengan prinsipprinsip syariah. Tetapi dalam implementasinya ada beberapa yang harus dibenahi oleh pihak CIMB Niaga Syariah, agar aspek kepatuhan terhadap prinsip-prinsip syariah yang sudah ditetapkan oleh Fatwa (DSN-MUI) No. 54/DSN-MUI/X/2006 bisa diimplementasikan dengan baik. Beberapa catatan dari penulis yaitu :

Pihak CIMB Niaga harus memberikan Pengetahuan produk (product knowledge) tentang Kartu Gold Syariah, agar marketing dan customer service mengetahui dengan jelas mengenai produk Kartu Gold Syariah. Terutama tentang hal-hal yang memang secara mendasar harus diketahui oleh para pengguna. Sehingga pengguna dapat mendapatkan informasi secara utuh tentang kartu kredit syariah tersebut. Serta sebaiknya dibedakan antara divisi kartu kredit syariah dan kartu kredit konvensional agar tidak terjadi kebingungan terhadap pengguna kartu kredit.

Pihak CIMB Niaga seharusnya tidak hanya menerapkan hal-hal pokok seperti akad, denda ta'wid, ketentuan fee dalam mengikuti Fatwa (DSN-MUI) No. 54/DSNMUI/X/2006, tetapi batasan-batasan yang telah di tetapkan juga harus diimplementasikan secara utuh agar pengguna kartu kredit syariah tersebut memang dalam menggunakan kartu kredit tersebut sesuai dengan prinsip-prinsip syariah, yang memamng sangat berbeda dengan kartu kredit konvensional dari ketentuan maupun fungsi penggunaanya.

\section{DAFTAR PUSTAKA}

Antonio, Muhammad Syafi'i, Bank Syariah : Dari Teori ke Praktek, Jakarta: Gema Insani, 2017 
Karim, Adiwarman, Bank Islam analisis Fiqih dan keuangan, Jakarta : Raja Grafindo

persada, 2010

Qaradhawi, Yusuf, Halal dan Haram, Bandung: Penerbit Jabal, 2014

Sulaiman, AW Ibrahim, Banking Cards Syariah Kartu Kredit dan Debit dalam Perspektif

Fiqih, Jakarta: Raja Grafindo Persada, 2006

Tarmizi, Erwandi, Muamalat Kontemporer, Bogor: Berkat Mulia Insani, 2017

\section{JURNAL}

Antonio, Muhammad Syafi' I, "Modal”, Majalah Islami Bulanan, Edisi No. 8, 1 Juni 2003), hal : 13

Firmanda, Hengki (2014) , Syariah card (Kartu Kredit Syariah) Ditinjau Dari Asas

Utilitas dan Maslahah, Jurnal Ilmu Hukum, 4 (2), 253-288

Website :

www.bi.go.id

www.cimbniaga.com

https://dsnmui.or.id 